\title{
Estimates of Projection Overlap and Zones of Convergence within Frontal-Striatal Circuits
}

\author{
Bruno B. Averbeck, ${ }^{1}$ Julia Lehman, ${ }^{2}$ Moriah Jacobson, ${ }^{2}$ and Suzanne N. Haber ${ }^{2}$ \\ ${ }^{1}$ Laboratory of Neuropsychology, National Institute of Mental Health, National Institutes of Health, Bethesda, Maryland 20892-4415, and ${ }^{2}$ Department of \\ Pharmacology and Physiology, University of Rochester School of Medicine and Dentistry, Rochester, New York 14642
}

Frontal-striatal circuits underlie important decision processes, and pathology in these circuits is implicated in many psychiatric disorders. Studies have shown a topographic organization of cortical projections into the striatum. However, work has also shown that there is considerable overlap in the striatal projection zones of nearby cortical regions. To characterize this in detail, we quantified the complete striatal projection zones from 34 cortical injection locations in rhesus monkeys. We first fit a statistical model that showed that the projection zone of a cortical injection site could be predicted with considerable accuracy using a cross-validated model estimated on only the other injection sites. We then examined the fraction of overlap in striatal projection zones as a function of distance between cortical injection sites, and found that there was a highly regular relationship. Specifically, nearby cortical locations had as much as $80 \%$ overlap, and the amount of overlap decayed exponentially as a function of distance between the cortical injection sites. Finally, we found that some portions of the striatum received inputs from all the prefrontal regions, making these striatal zones candidates as information-processing hubs. Thus, the striatum is a site of convergence that allows integration of information spread across diverse prefrontal cortical areas.

\section{Introduction}

Corticostriatal connections, the front end of the cortical-basal ganglia-thalamocortical loops, play a central role in decision making. For example, object and action values are represented across frontal cortical regions (Padoa-Schioppa and Assad, 2006; Roesch and Olson, 2007; Kennerley and Walton, 2011; Kennerley et al., 2011; Wallis and Kennerley, 2011) and their striatal targets (Takikawa et al., 2002; Schultz et al., 2003; O'Doherty et al., 2004). Further, pathology in this circuit is implicated in a wide range of psychiatric disorders, including schizophrenia, obsessive compulsive disorder, addiction, and impulse control disorders (Davis et al., 1991; Weinberger et al., 1992; Goodman et al., 2010; Kegeles et al., 2010; van den Heuvel et al., 2010; Cilia et al., 2011; Ersche et al., 2012). Thus, these circuits appear to play an important role in decision processes, and pathology in these circuits can lead to psychiatric disorders. Therefore, understanding the detailed architecture of frontal-striatal projections will provide an important foundation for understanding their physiology in relation to behavior.

There has been growing interest in broad cortical networks, which feature nodes (or connections hubs) that integrate and distribute information across multiple regions (Buckner et al., 2008). While the overall topographic organization of the cortico-

\footnotetext{
Received Dec. 19, 2012; revised April 23, 2014; accepted May 25, 2014.

Author contributions: B.B.A., J.L, and S.N.H. designed research; B.B.A., J.L., M.J., and S.N.H. performed research; B.B.A. analyzed data; B.B.A. and S.N.H. wrote the paper.

This work was supported in part by the Intramural Research Program of the National Institute of Mental Health (B.B.A.); and National Institute of Mental Health Grants MH 045573 and MH 086404 (S.N.H.)

The authors declare no competing financial interests.

Correspondence should be addressed to Bruno B. Averbeck, PhD, Laboratory of Neuropsychology, NIMH/NIH, Building 49 Room 1B80, 49 Convent Drive MSC 4415, Bethesda, MD 20892-4415. E-mail: bruno.averbeck@nih.gov. DOI:10.1523/JNEUROSCI.5806-12.2014

Copyright $\odot 2014$ the authors $\quad 0270-6474 / 14 / 339497-09 \$ 15.00 / 0$
}

striatal pathways has been well described (Alexander et al., 1986; Middleton and Strick, 2000; Kelly and Strick, 2004; Bostan et al., 2013), recent evidence has shown that fibers from functionally diverse cortical areas also overlap within the striatum (Haber et al., 2006; Draganski et al., 2008). These regions of overlap may be the striatal equivalents of cortical hub connections for integrating information from diverse cortical areas that represent different components of decision processes or for associating values to actions and stimuli (Seo et al., 2012). Thus, for example, each prefrontal region seems to be enriched with signals related to different aspects of the decision process (Kennerley et al., 2011). However, collectively these areas work together in developing an action plan, likely in conjunction with the striatum.

In this manuscript we quantified corticostriatal projections using statistical models to address four questions: (1) Were the patterns of striatal projections consistent across animals? (2) What was the extent of the overlap between terminal fields from different cortical regions in the striatum, and to what extent did this overlap depend on the distance between cortical injection sites within the frontal cortex? (3) Did any frontal subregions show more overlap than the others? (4) Could we identify specific striatal regions that were enriched with a convergence of inputs from the different prefrontal cortical areas? Given that general projection patterns are likely to be similar between human and nonhuman primates (Draganski et al., 2008), these data will also help guide striatal segmentation in human imaging studies.

\section{Materials and Methods}

All injection were done on male, macaque monkeys. To examine the organization of frontal corticostriatal connections, we injected anterograde or bidirectional tracers (Fig. 1, Table 1) into the dorsal anterior cingulate cortex (dACC, area 24), the ventral medial prefrontal cortex (vmPFC, areas 24/14, part of 10), the orbital cortex (areas, 11, 13, 14, 12), 


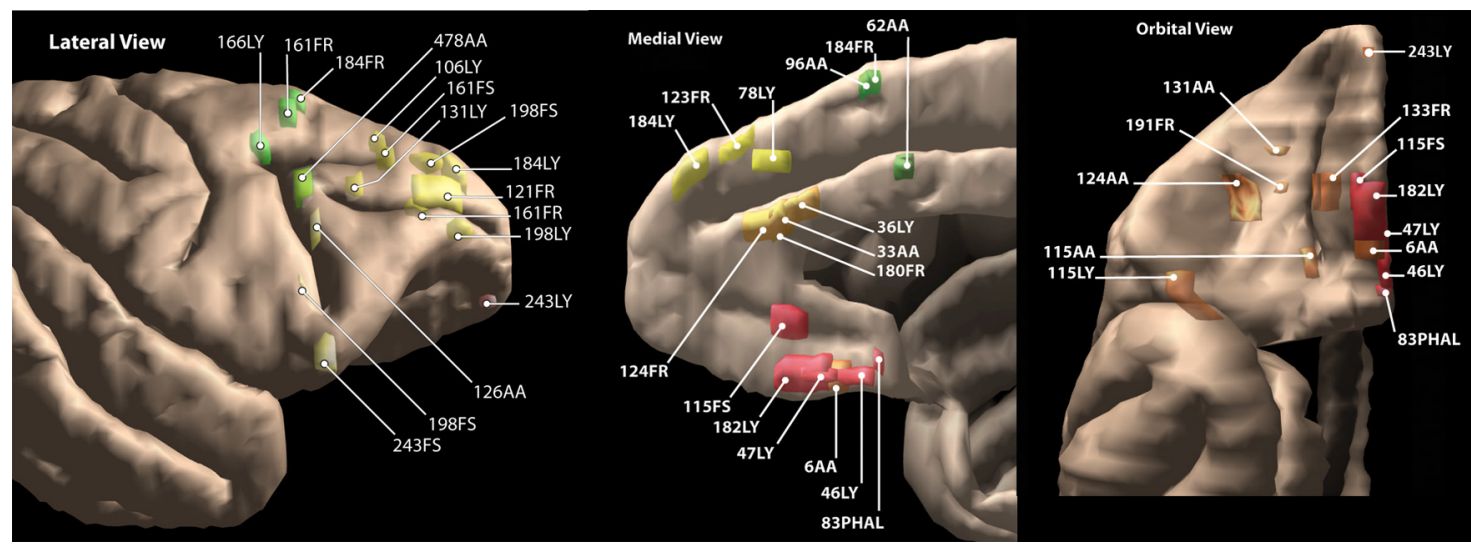

Figure 1. Cortical injection sites.

Table 1. Injection locations in cortex

\begin{tabular}{|c|c|c|c|c|c|}
\hline Location & $\begin{array}{l}\text { Injection } \\
\text { ID }\end{array}$ & $\begin{array}{l}\text { A-P } \\
\text { distance } \\
(\mathrm{mm})\end{array}$ & $\begin{array}{l}\text { Distance } \\
\text { from dorsal } \\
\text { peak }(\mathrm{mm})\end{array}$ & $\begin{array}{l}\text { Injection } \\
\text { volume } \\
\left(\mathrm{mm}^{3}\right)\end{array}$ & $\begin{array}{l}\text { Cortical } \\
\text { circumference }\end{array}$ \\
\hline \multicolumn{6}{|l|}{ vmPFC } \\
\hline Area 14/25 & Vm46LY & 7.20 & 66.40 & 1.13 & 88.97 \\
\hline Area 14/25 & vm47LY & 9.60 & 64.83 & 1.36 & 88.58 \\
\hline Area 25 & vm83PH & 6.00 & 72.08 & 0.70 & 93.08 \\
\hline Area 14 PAI & $6 \mathrm{AA}$ & 8.40 & 63.30 & 4.64 & 89.30 \\
\hline Area 14 & 182LY & 10.80 & 62.69 & 14.17 & 90.33 \\
\hline Area $32+$ & $115 \mathrm{FS}$ & 12.00 & 65.68 & 4.44 & 89.55 \\
\hline \multicolumn{6}{|l|}{$\mathrm{OFC}$} \\
\hline Area 11 & 131AA & 15.00 & 35.34 & & 73.81 \\
\hline Area 11 & $133 \mathrm{FR}$ & 12.00 & 51.74 & 5.49 & 89.55 \\
\hline Area 11/12 & $124 \mathrm{AA}$ & 12.00 & 44.01 & 4.93 & 89.55 \\
\hline Area 11/13 & 191FR & 12.00 & 47.09 & 0.41 & 89.55 \\
\hline Area 13 & 0115AA & 7.20 & 59.93 & 1.22 & 88.97 \\
\hline Area OP & $115 \mathrm{LY}$ & 6.00 & 55.76 & 5.57 & 93.08 \\
\hline Area 10 & 243LY & & 17.36 & & \\
\hline \multicolumn{6}{|l|}{$\mathrm{dACC}$} \\
\hline Area 24b & 180FR & 12.60 & -14.07 & 4.94 & 86.02 \\
\hline Area 24b, c & C $36 L Y$ & 12.00 & -15.89 & 7.08 & 89.55 \\
\hline Area $24 c$ & C $33 A A$ & 12.00 & -14.48 & 0.86 & 89.55 \\
\hline Area 32/24 & $124 \mathrm{FR}$ & 13.20 & -15.83 & 10.69 & 83.41 \\
\hline $24 c$ & C $62 \mathrm{AA}$ & 4.80 & -10.74 & 1.88 & 104.11 \\
\hline \multicolumn{6}{|l|}{ dPFC } \\
\hline Area 9 & $978 \mathrm{LY}$ & 13.20 & -5.57 & 3.58 & 83.41 \\
\hline Area 9 & $123 F R$ & 16.80 & -2.32 & & 62.64 \\
\hline Area 10/9 & 184LY & 18.60 & -1.07 & 12.58 & 49.99 \\
\hline Areas 9-46 & $166 \mathrm{FR}$ & 15.00 & 12.04 & & 73.81 \\
\hline Areas 9 and 46 & $121 F R$ & 17.40 & 5.66 & 13.38 & 57.50 \\
\hline Areas 9-46 & 131LY & 11.40 & 8.45 & 3.03 & 92.27 \\
\hline Area 46 & $98 \mathrm{AA}$ & 16.80 & 9.89 & & 62.64 \\
\hline Area 9 and $8 a, d(9+)$ & $161 \mathrm{FS}$ & 13.80 & 4.86 & 2.53 & 80.87 \\
\hline $\begin{array}{l}\text { Frontal eye field } \\
\text { (supplementary eye } \\
\text { field) areas }\end{array}$ & $478 \mathrm{AA}$ & 7.80 & 18.70 & 5.23 & 90.11 \\
\hline \multicolumn{6}{|l|}{ VIPFC } \\
\hline Area 47 & $243 \mathrm{FS}$ & & 36.28 & & 94.94 \\
\hline Area 45 & $126 \mathrm{AA}$ & 73 & -8.40 & 23.94 & 89.3 \\
\hline Area 44/47 & $196 \mathrm{FS}$ & 79 & -7.20 & 29.21 & 88.97 \\
\hline \multicolumn{6}{|l|}{ Premotor cortex } \\
\hline Area 6 (anterior) & $96 \mathrm{AA}$ & 7.20 & -1.48 & & 88.97 \\
\hline F7, Area 6 & 161FR & 6.60 & 2.87 & 5.23 & 92.28 \\
\hline Area 6 (dorsal anterior) & $166 \mathrm{LY}$ & 4.80 & 10.44 & & 104.11 \\
\hline Premotor (rostral) & 184FR & 7.20 & 0.66 & 3.18 & 88.97 \\
\hline
\end{tabular}

the dorsolateral prefrontal cortex (dlPFC, areas 10, 9 and 46), the frontal eye fields (area 8), and the premotor cortex (area 6), as described previously in detail (Haber et al., 2006; Calzavara et al., 2007). No injections were placed in the motor cortex (area 4). Corticocortical labeling was used to verify the specificity of the injection sites. We charted the entire projection field throughout the striatum for each case. In addition to the traditional charting of individual fibers, we outlined the dense (or focal) projection fields for each case to create 3-D maps of the fields. These 3-D maps were then compiled to delineate the entire striatal region that receives the primary input from prefrontal and premotor areas. We used the data from the individual animals collected from these previous studies (a total of 34 injection sites; Fig. 1, Table 1) to create our model.

Surgery and tissue preparation. Twenty-eight adult macaque monkeys (20 Macaca nemestrina and 8 Macaca fascicularis) were used for the tracing studies. All experiments were conducted in accordance with the Guide for the Care and Use of Laboratory Animals (National Research Council, 1996) and were approved by the University of Rochester's University Committee on Animal Resources. Intramuscular injection of ketamine $(10 \mathrm{mg} / \mathrm{kg})$ was used for initial tranquilization, and maintained by isoflurane. Temperature, heart rate, and respiration were monitored throughout the surgery. Monkeys were placed in a David Kopf Instruments stereotax, and a craniotomy $(2-3 \mathrm{~cm})$ was made over the region of interest. Small dural incisions were then made at injection sites. Lucifer yellow (LY), Fluororuby (FR), or fluorescein (FS) conjugated to dextran amine [ $40-50 \mathrm{nl}, 10 \%$ in $0.1 \mathrm{M}$ phosphate buffer (PB), pH 7.4; Invitrogen] were pressure injected over 10 min using a $0.5 \mu \mathrm{l}$ Hamilton syringe. Twelve to $14 \mathrm{~d}$ later, monkeys were again deeply anesthetized and perfused with saline, followed by a $4 \%$ paraformaldehyde $/ 1.5 \%$ sucrose solution in $0.1 \mathrm{M} \mathrm{PB}, \mathrm{pH}$ 7.4. Brains were postfixed overnight and cryoprotected in increasing gradients of sucrose (10, 20, and 30\%; Haber et al., 2006).

Immunocytochemistry was performed on $50 \mu \mathrm{m}$, free-floating sections (one in eight for each tracer). Tissue was treated with $10 \%$ methanol and 3\% hydrogen peroxide in $0.1 \mathrm{M} \mathrm{PB}$ to inhibit endogenous peroxidase activity, rinsed $1-2 \mathrm{~h}$ in $\mathrm{PB}$ with $0.3 \%$ Triton X-100 (TX; Sigma-Aldrich), and were preincubated in $10 \%$ normal goat serum and $0.3 \% \mathrm{TX}$ in PB for $30 \mathrm{~min}$. Tissue was then placed in the primary anti-LY (1:3000 dilution; Invitrogen), anti-FS (1:1000; Invitrogen), or anti-FR (1:1000; Invitrogen), and after rinsing was incubated in biotinylated secondary antibody, followed by incubation with the avidin-biotin complex solution (Vectastain ABC kit, Vector Laboratories) with visualization using standard $\mathrm{DAB}$ procedures. Staining was intensified by incubating the tissue for 5-15 min in a solution of $0.05 \%$ 3,3-diaminobenzidine tetrahydrochloride, $0.025 \%$ cobalt chloride, $0.02 \%$ nickel ammonium sulfate, and $0.01 \% \mathrm{H}_{2} \mathrm{O}_{2}$ to yield a black reaction product. Sections were mounted, dehydrated, defatted in xylenes, and coverslipped with Permount.

Typically, the injection site was centered in superficial cortical layers. Tracers spread some distance from the center and typically include all the layers. We centered the injections a bit more dorsal as we did not want to risk spread into the underlying white matter and therefore involve pass- 
STRZ97 (anterior $3.6 \mathrm{~mm}$ )
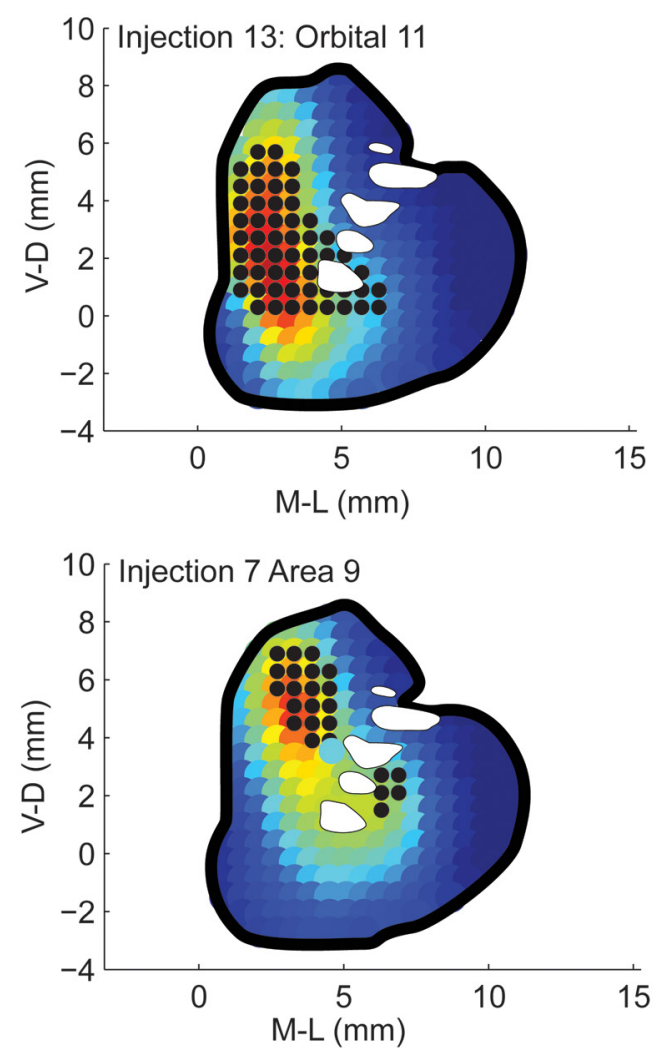
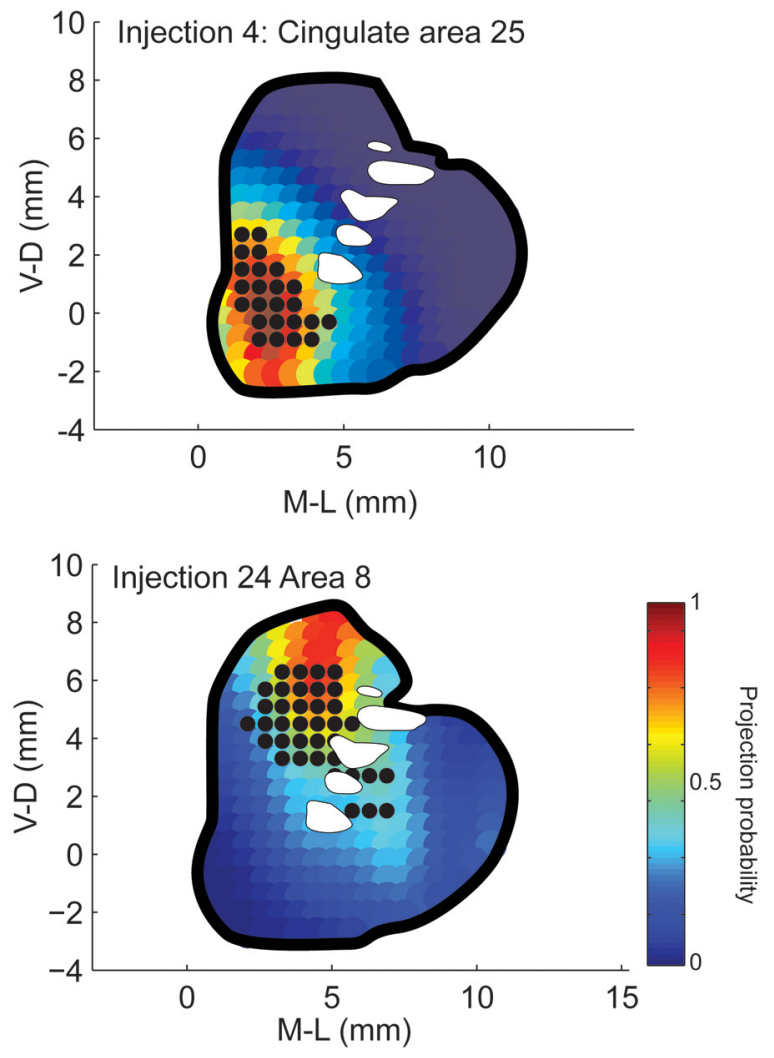

Figure 2. Predicted (heat map) and actual (black dots) projections into the striatum from four different cortical injections.

ing fibers. We eliminated injection sites that did not include layer 5 and did not show robust labeling in the striatum. Fiber distributions for each case were charted throughout the rostrocaudal striatum. The general corticocortical labeling in each case was consistent with expected results from on-target injections (Barbas and Pandya, 1989; Carmichael and Price, 1996). For the anatomical boundaries of the ACC, the orbitofrontal cortex (OFC), and the dlPFC, we used the atlas by Paxinos et al. (2000) in conjunction with detailed anatomical descriptions (Barbas and Pandya, 1989; Petrides and Pandya, 2002).

Three-dimensional reconstructions. We have developed a method to reconstruct the dense terminal fields in 3-D to address where each projection is located within the striatum and to develop a 3-D global atlas that combines different projections to compare terminal fields across multiple cases. We first determined each area of dense projection using a $1.6 \times$ objective and Neurolucida software (MicroBrightfield) to directly outline the region. Boundaries for each dense projection field were checked for accuracy with the chartings that were performed at higher magnification ( $10 \times$ objective). For each case, a stack of 2-D coronal sections was created from Neurolucida chartings and Nissl images. This stack was imported into IMOD, a 3-D rendering program (Boulder Laboratory for 3D Electron Microscopy of Cells, University of Colorado, Boulder, CO; Kremer et al., 1996), and a 3-D reconstruction for each dense projection field was created for each case separately.

To merge several cases together, we developed a reference atlas of the striatum from one animal by sampling one in four sections (at $200 \mu \mathrm{m}$ intervals) throughout the striatum, of which two were photographs taken of the block face while sectioning and four were Nissl-stained sections. Data from each case were then transposed into the reference striatum using landmarks of key internal structures surrounding the striatum. After the transposition of the contours surrounding the dense projection fields from each case, every contour in the reference model was compared with that in the individual case to ensure that the medial-lateral (M-L), dorsal-ventral (D-V), and anterior-posterior (A-P) placements and relative size were accurate. For this study, we used only the dense projection fields outlined on the photographs of the block faces (every $600 \mu \mathrm{m}$ ) to decrease any distortion created by processing the tissue.

To generate data for model fitting, a grid was placed on each scanned striatal section, with the $\mathrm{V}-\mathrm{D}$ and $\mathrm{M}-\mathrm{L}$ location of the grid aligned across sections of the striatum. The grid had $600 \mu \mathrm{m}$ squares, and adjacent tissue sections were separated by $600 \mu \mathrm{m}$, such that each grid location defined a $600 \mu \mathrm{m}$ isotropic voxel. For each cortical injection, all grid locations that received a dense projection from that cortical injection were given a value of 1 and all grid locations that did not receive a projection were given a value of 0 . Thus, the projection zone of each cortical injection was defined in a 3-D coordinate system with $600 \mu \mathrm{m}$ voxels. For example, in Figure 2, the black dots indicate grid locations that were in that A-P slice and that received a projection from the corresponding cortical injection location. The locations of cortical injection sites were also defined on a 2-D map of cortex, with coordinates given by distance from the cortical crown (dorsal peak of the cortex) and A-P location.

Data analysis. Cortical projections into the striatum were modeled using binary logistic regression (Christensen, 1997; Menard, 2002) and kernel density estimation (Hastie et al., 2001). All analyses were carried out with Matlab, including the Statistics Toolbox (Mathworks). The analysis proceeded in two steps. First, the probability that a single voxel in the striatum received a projection from a given location in the cortex was modeled as follows in Equation 1: $p_{x, y, z}=g\left(a_{0}+d_{c} a_{1}+d_{a p} a_{2}\right)$, where $d_{c}$ was the distance of an injection from the cortical crown, $d_{a p}$ was the A-P position of the injection, and $x, y, z$ was the location of the voxel in the striatum. The variables $a_{0}, a_{1}, a_{2}$ were the regression coefficients that were fit to the data. The $a_{0}$ term is the model intercept. The $a_{1}$ term characterizes the effect of the distance to the cortical crown and the $a_{2}$ term models the effect of the A-P distance on the probability of a projection. The $x$ value of each voxel was its M-L location, $y$ was its $\mathrm{D}-\mathrm{V}$ location, and $z$ was its A-P (slice) location. The link function $g(x)$ was the logistic function. We also examined models that allowed for an interaction between $d_{c}$ and $d_{a p}$, but the addition of this parameter failed to improve the fit. This 
model was fit separately for each voxel in the striatum. Following this, the projection probabilities $p_{x, y, z}$ were smoothed using a Gaussian kernel as follows:

$$
\begin{gathered}
P_{x, y, z}^{s}=\frac{\sum_{x^{\prime}, y^{\prime}, z^{\prime}} H(0, Q) P_{x^{\prime}, y^{\prime}, z^{\prime}}}{\sum_{x^{\prime}, y^{\prime}, z^{\prime}} H(0, Q)} \\
\text { with } H(0, Q)=\exp \left(-\Delta v^{T} Q^{-1} \Delta v\right) \\
\quad x-x^{\prime} \\
\text { The variable } \Delta v=\begin{array}{cccc}
0.9 & 0 & 0 \\
& y-y^{\prime} \\
& z-z^{\prime}
\end{array} \text { and the matrix } Q=\begin{array}{ccc}
0 & 3.2 & 0 \\
0 & 0 & 5.7
\end{array} .
\end{gathered}
$$

The values in $Q$ define the width of the Gaussian kernel in $x, y, z$ coordinates. These values were optimized using a grid search followed by gradient descent on the likelihood function. We also examined models that allowed off-diagonal elements to be nonzero, but the addition of these free parameters did not improve the fit of the model. The loglikelihood function for the overall model was as follows:

$$
l l=\sum_{i, x, y, z} \log \left(l_{i, x, y, z} p_{x, y, z}^{s}+\left(1-l_{i, x, y, z}\right)\left(1-p_{x, y, z}^{s}\right)\right)
$$

where $l_{i, x, y, z}$ indicated whether there was a projection to that location from a given injection, $i$, in cortex.

All modeling was done using leave-one-injection-out cross-validation. Thus, one of the 34 injections was removed from the data, and then Equation 1 was fit and the projection probabilities were smoothed using Equation 2. This estimate was then used to compute the likelihood on the single injection not used to fit the model. All estimated projections shown in the manuscript are also derived from a model fit without using the corresponding injection. Thus, the model provides an estimate of how well an injection location that the model has never seen can be predicted.

For calculation of the fraction of overlapping voxels as a function of distance, we first computed the distance between injection sites using the following equation:

$$
d(i, j)=\sqrt{\left(d_{c}(i)-d_{c}(j)\right)^{2}+\left(d_{a p}(i)-d_{a p}(j)\right)^{2}}
$$

We took into account that the distance from the crown was periodic and found the actual distance between injections in periodic coordinates. We then calculated the fraction of overlap in the striatal projection according to the following equation:

$$
O(i, j)=\frac{\sum_{x, y, z}\left(l_{i, x, y, z} \& l_{j, x, y, z}\right)}{\min \left(\sum_{x, y, z} l_{i, x, y, z}, \sum_{x, y, z} l_{j, x, y, z}\right)}
$$

where the \& operator returns 1 if both injection sites, $i$ and $j$ projected to the striatal voxel, $x, y, z$, and zero otherwise. The numerator was normalized by the projection, which had minimum volume.

\section{Results}

The model was based on striatal projection zones from 34 well placed injection sites that were confined to specific frontal regions. First we developed a model to predict the striatal projection zones for arbitrary frontal cortical injection locations to establish the consistency of the striatal projection zones across individual cases, given that injections were placed in different animals. This also demonstrated the reliability for predicting projection fields for cortical regions for which we do not have tracer injections. The model created a highly statistically significant $\left(\chi_{3}^{2}\right.$ $=18,880, p<0.001)$ result that correctly predicted the projection locations with $72 \%$ accuracy. That is, the prediction of whether a single isotropic $600 \mu \mathrm{m}$ voxel did or did not receive a projection from a given cortical location across all injections. The predicted striatal projection zones consistently showed an accurate placement compared with the actual projection zones (Fig. 2). The prediction for injection 24 is slightly more dorsal than the

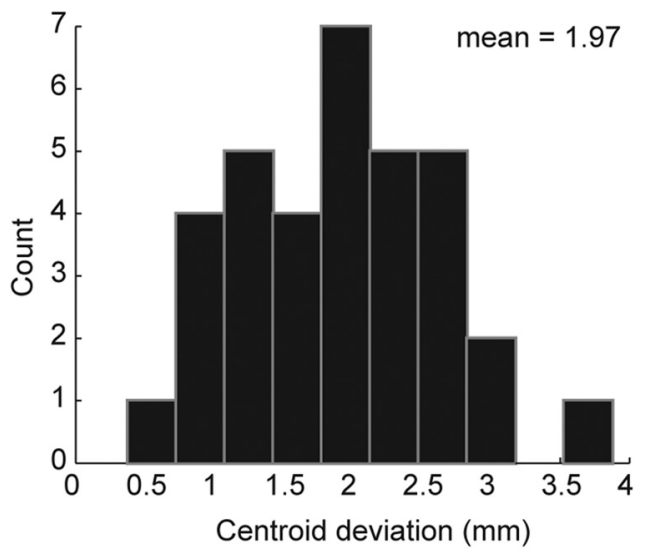

Figure 3. Deviation between predicted and measured centroid of striatal projection zone.

actual projection, which illustrates a case where the model misses somewhat. We also found that the center of the predicted projection zone (the centroid) was on average within $2 \mathrm{~mm}$ of the actual projection centroid (Fig. 3). This was consistent across injections sites even though this was not the specific metric for which the model was optimized.

The optimized fit of the model also provided insight into the distribution of corticostriatal projection zones in 3-D space (M-L, D-V, and A-P). Specifically, the optimal 3-D Gaussian smoothing window had SDs of $0.95,1.79$, and $2.39 \mathrm{~mm}$ in the $x$ (M-L), $y(\mathrm{D}-\mathrm{V})$, and $z(\mathrm{~A}-\mathrm{P})$ directions. Overall, we found that PFC projection fields were distributed over longer distances in the A-P direction compared with the $\mathrm{M}-\mathrm{L}$ or $\mathrm{D}-\mathrm{V}$ directions. Interestingly, the M-L spread of terminals from a given cortical area within the striatum was the most limited. This consistent finding suggests that the frontal cortical projections are generally elongated through the A-P coordinate, as shown previously for a few cases (Selemon and Goldman-Rakic, 1985). In summary, striatal projection zones of individual frontal cortical injection sites showed considerable reliability across animals and followed a statistically predictable pattern.

Second, the model also predicted that distance between cortical injection sites might be related to the amount of overlap in striatal projections. We examined the fraction of overlap of striatal projection zones, as a function of distance between cortical injection sites (Fig. 4). The results demonstrated that the distance between two injected areas is related to the extent of terminal zone overlap in the striatum from those areas. Injection sites that are within $2 \mathrm{~mm}$ have $\sim 80 \%$ overlap, while those separated by 20-30 mm have $20 \%$ overlap. For example, a pair of injections in vmPFC (areas 25/14 and 32) was $2.4 \mathrm{~mm}$ apart and their terminal zones overlapped $80 \%$ within the striatum (Fig. $5 A$ ). By comparison, the overlap between an injection in vmPFC (32) and dorsal PFC (dPFC; 9/46) injection was $21 \%$ with a separation of $28.5 \mathrm{~mm}$. The overlap between another pair of vmPFC (25/14) and dPFC (9/46) injections was $5 \%$ with the injection sites separated by $29 \mathrm{~mm}$ (Fig. $5 A$ ). A pair of injections (Fig. $5 B$ ), one in OFC (11) and one in dPFC (9), separated by $38 \mathrm{~mm}$, overlapped by $4 \%$. The overlap between an injection in OFC (11) and one in dACC (24) was 37\% at a distance of $22 \mathrm{~mm}$. Finally, the overlap between an injection in dACC (24) and dPFC (9) was $26 \%$ at a distance of $21 \mathrm{~mm}$. Thus, the relationship between distance and overlap in the striatum, on average, was well captured by an exponential relationship (Fig. 4).

However, as also can be seen (Figs. 4, 5), there was variability around the mean estimate. Some pairs of injections showed more 


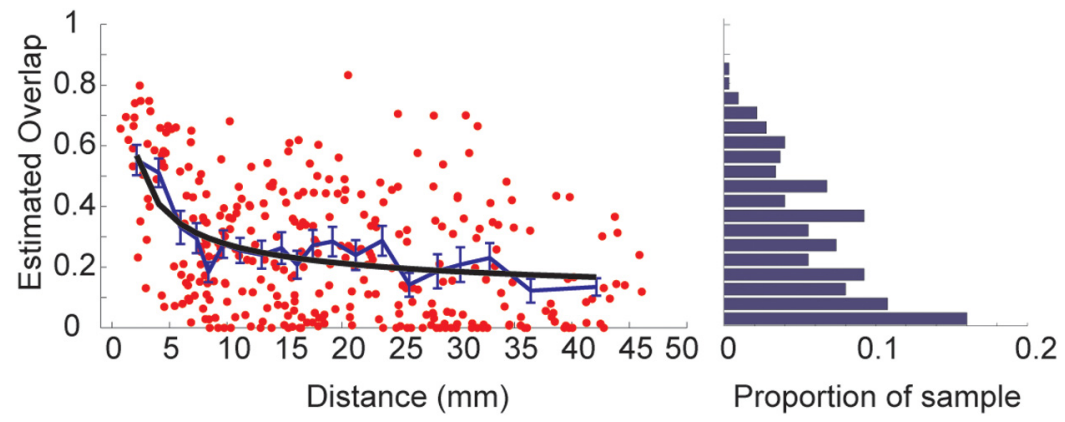

Figure 4. Measured fraction of overlap in striatal projection volume as a function of distance between cortical injection sites. Black line given by the following: overlap equals $0.04 e^{3.2 d-0.2}$. Blue line given by average in each of 20 bins with an equal number of points in each. Right, Proportion of the sample (red dots) that have the indicated overlap. This is calculated by summing the number of red dots in each overlap bin (bar on the bar graph) and dividing by the total number of dots.

and some less overlap than would be expected, given the model, and the distance between the injection sites. Therefore, we next examined whether any of this remaining variability might be consistently related to the frontal region-i.e., orbital, ventral medial, etc.- of the injection sites. We first examined the striatal projection volume of injections in each frontal region for the subset of injection for which we had injection volume information $(N=23$; Fig. $6 A)$. We found that vmPFC sites had the smallest striatal projection volumes, followed by dPFC, dACC, and OFC. However these differences were not statistically significant $\left(F_{(3,16)}=2.34, p=0.112\right)$. We next examined the fraction of overlap for all pairs in which each pair had one site in each of the corresponding regions (Fig. 6B). This analysis was performed on the overlap, after controlling for the overlap expected based upon the distance between the injections, by using the residual from the regression fit. We found that orbital injection sites had more overlap than would be expected based only upon the distance between injection sites, followed by dACC, lateral PFC, and then vmPFC (Fig. 6B). These differences were statistically significant $\left(F_{(3,213)}=10.58, p<0.001\right)$. Post hoc comparisons (Bonferroni corrected) showed that OFC had significantly more overlap than vmPFC $(p<0.05)$ and OFC had significantly more overlap than dPFC $(p<0.05)$ but none of the other pairs were significantly different $(p>0.05)$.

In the final analysis, we calculated the number of cortical regions that projected to each voxel within the striatum. That is, we used the data to determine not only that inputs from different functional cortical areas converged, but where that convergence occurred and between how many cortical regions (Fig. 7). This analysis showed that the medial caudate nucleus, primarily rostral to the anterior commissure, receives convergent input from the OFC, dACC, vmPFC, dPFC, and ventrolateral PFC (vlPFC; Fig. 7, yellow). The area is limited by the vlPFC projections. Thus the region with convergent projections from the vmPFC, OFC, $\mathrm{dACC}$, and $\mathrm{dPFC}$ is more extensive (indicated in dark red). In contrast, the ventral striatum and the posterior and lateral striatum receive projections from fewer prefrontal cortical regions.

\section{Discussion}

We used a computational model to characterize the consistency of cortical projection zones into the striatum between individual cases and found that they followed a highly regular pattern. Specifically, we were able to predict the locations in the striatum that received inputs from a given cortical location. The location of projection centroids (i.e., the mean location in 3-D coordinates) were also estimated by the model with an average of $2 \mathrm{~mm}$ error relative to the data. Following this, we examined the overlap in the striatal projection zones for pairs of cortical injection sites and found that there was an exponential decay in overlap as a function of distance. Overlap in striatal projections of sites separated by $<5 \mathrm{~mm}$ was $>50 \%$. The overlap decreased to $\sim 20 \%$ at sites separated by $30 \mathrm{~mm}$. We further found that orbital injection sites tended to have more overlap with injection sites from other cortical areas than would be expected based only on distance between sites, although this additional overlap was only $\sim 4 \%$. In a final analysis we identified a region of the striatum in the anterior caudate that received projections from across the prefrontal cortical regions. This area of the striatum likely functions as a hub, integrating information from diverse sources. In contrast to this, some striatal regions, particularly posterior and lateral portions, receive inputs from only a few prefrontal regions, and therefore they may serve more specialized computational roles.

\section{Cortical surface location predicts projection zones}

Given the putative role of frontal-striatal circuits in many psychiatric conditions (Pantelis et al., 1997; van den Heuvel et al., 2010), the ability to further our understanding of corticostriatal connections is an important goal. Our statistical model shows that there is a highly regular organization of the projection zones, with respect to location on the cortical surface. Specifically, knowing only the location of a cortical injection site in A-P and D-V coordinates allows one to predict, with a high degree of accuracy, where it will project in the striatum. Moreover, these predictions were possible despite the fact that injections were done in different animals, demonstrating a high degree of consistency across monkeys.

\section{Terminal field convergence between adjacent and distant cortical areas}

Much of the thinking about the corticostriatal system has been driven by the idea that cortical inputs through the basal ganglia follow independent paths (Alexander et al., 1986). Convergence of connections in the striatum from distant cortical areas that themselves are interconnected has been shown (Yeterian and Van Hoesen, 1978). In addition, recent data in both monkeys and humans suggest that different frontal-cortical areas have overlapping projection zones (Haber et al., 2006; Draganski et al., 2008). The extent and nature of this overlap has, however, not been analyzed directly. The present results show that terminal fields from neighboring locations in cortex project to overlapping regions in the striatum. Importantly, given the size of the projection zone from individual cortical injection sites in the striatum, only cortical sites separated by relatively large distances will lead to completely nonoverlapping striatal projection zones. This is consistent with previous reports that have shown that projections from medial, lateral, and orbitofrontal cortex are topographically organized and have relatively minimal overlap (Kemp and Powell, 1970; Yeterian and Pandya, 1991).

We further characterized the amount of overlap in the striatum for pairs of injection sites. Our analysis showed a regular relationship, such that the fraction of overlap dropped exponentially with distance between injection sites. Neighboring sites had 
A
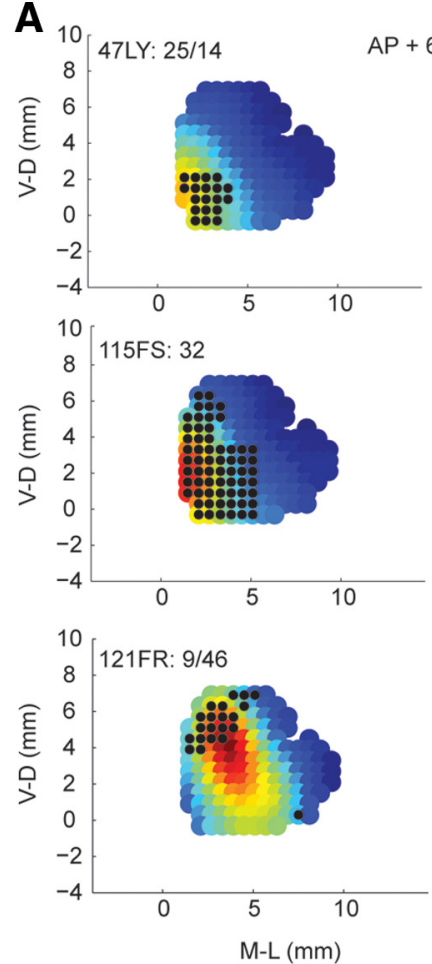
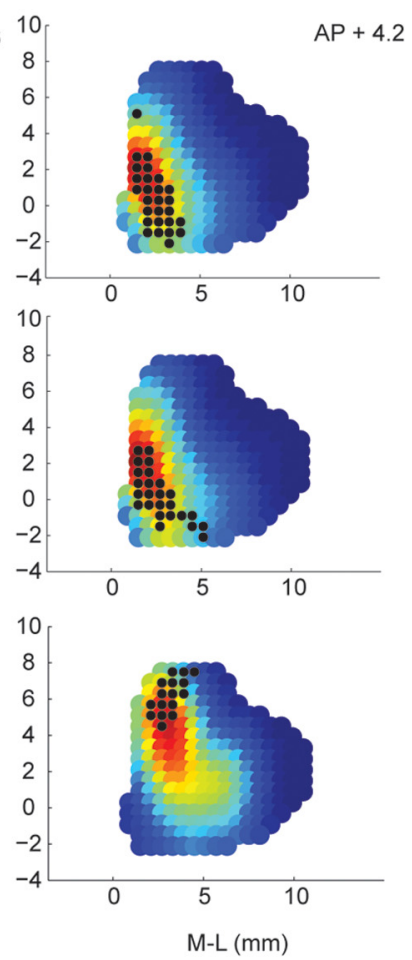
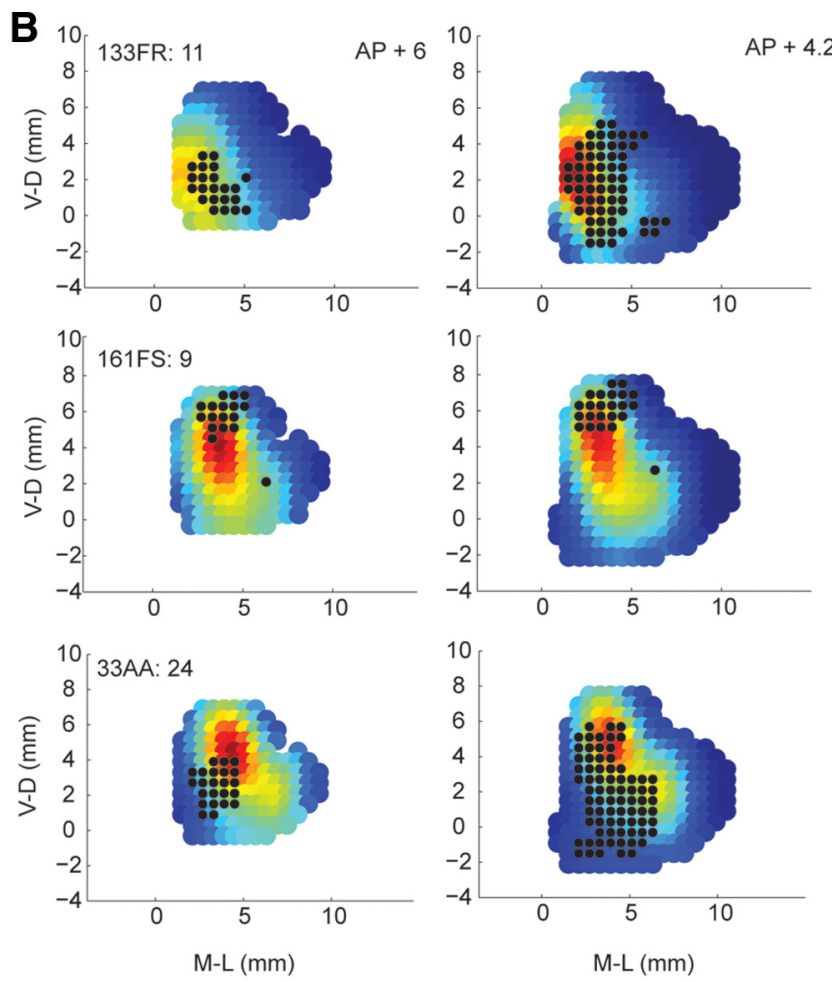

Figure 5. Examples of overlap. Each plot shows a heat map (color bar as in Fig. 2, where saturated red is a probability of 1). The black dots are the voxels that actually received a projection. $\boldsymbol{A}$, Striatal projection zones of an injection in area 25/14 (top row), area 32 (middle row), and area 9/46 (bottom row). $\boldsymbol{B}$, Striatal projection zones of injections in areas 11 (top row), 9 (middle row), and 24 (bottom row).

up to $80 \%$ overlap. Importantly, however, even sites separated by $3 \mathrm{~cm}$ overlapped by $\sim 15 \%$. While one might expect that terminals from adjacent cortical regions (and therefore, likely functionally related ones) would overlap within the striatum, the idea that terminals from distant cortical regions would also overlap, albeit to a lesser extent, is less expected. This indicates that the cortical connections from distant regions, but not necessarily functionally similar areas, converge within the monkey striatum. These overlaps may be important for integrating information across diverse functional domains. For example, terminals from regions of vmPFC and $\mathrm{dPFC}$, showed an overlap of $21 \%$, indicating that the striatum may play some role in modulating information across reward processing and executive function. Thus, the data support the idea that, although the striatum may be functionally organized, each area does not operate in complete isolation from other regions.

Finally we identified regions within the striatum that receive convergent inputs from multiple cortical regions. Most notably, there appears to be a region within the medial, rostral caudate nucleus to which axons terminate from all prefrontal regions. These vlPFC fibers, which also terminate in the rostral, ventral putamen, travel long distances through the lateral parts of the striatum to reach the medial caudate nucleus. These areas of overlap in striatal projection zones provide a substrate for integration of information from relatively distant cortical areas. For

A
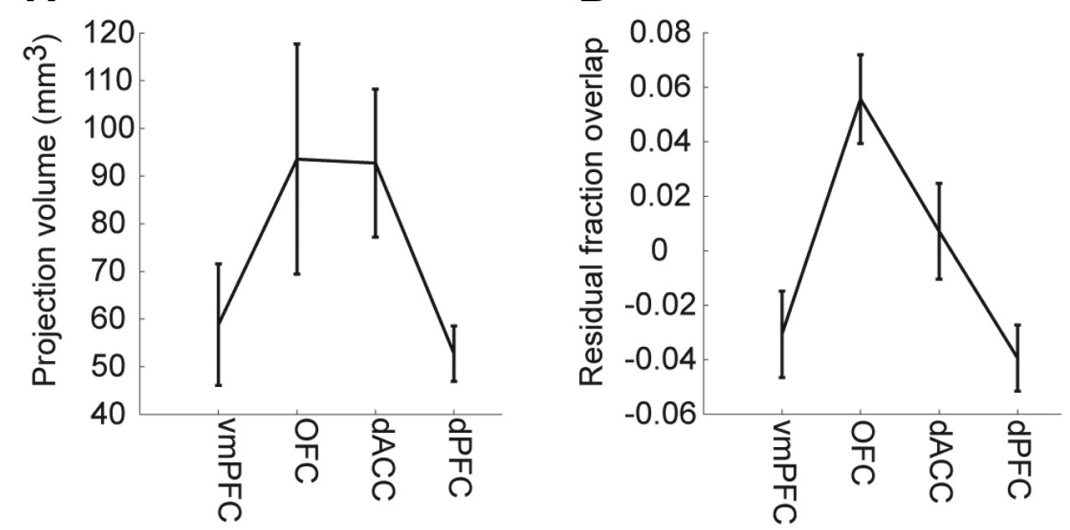

Figure 6. Properties of striatal projections examined separately for frontal regions. $A$, Total projection volume of each injection by frontal region. $\boldsymbol{B}$, Residual fraction of overlap, after accounting for distance between injections.

example, this overlap may allow integration of motivational and reward-related information, enriched in orbital and ventralmedial prefrontal areas, with information relevant to executive and motor processes, enriched in lateral-prefrontal and motor cortex.

Our results quantify previous observations on frontal corticostriate organization. These studies have shown that neighboring areas of cortex project to neighboring regions of the striatum, and that the head of the caudate is a site of convergence for prefrontal projections (Kemp and Powell, 1970; Yeterian and Pandya, 1991). Our analysis does not include data from parietal cortex. However, previous studies show that neighboring parietal areas project to neighboring striatal areas (Kemp and Powell, 1970; 

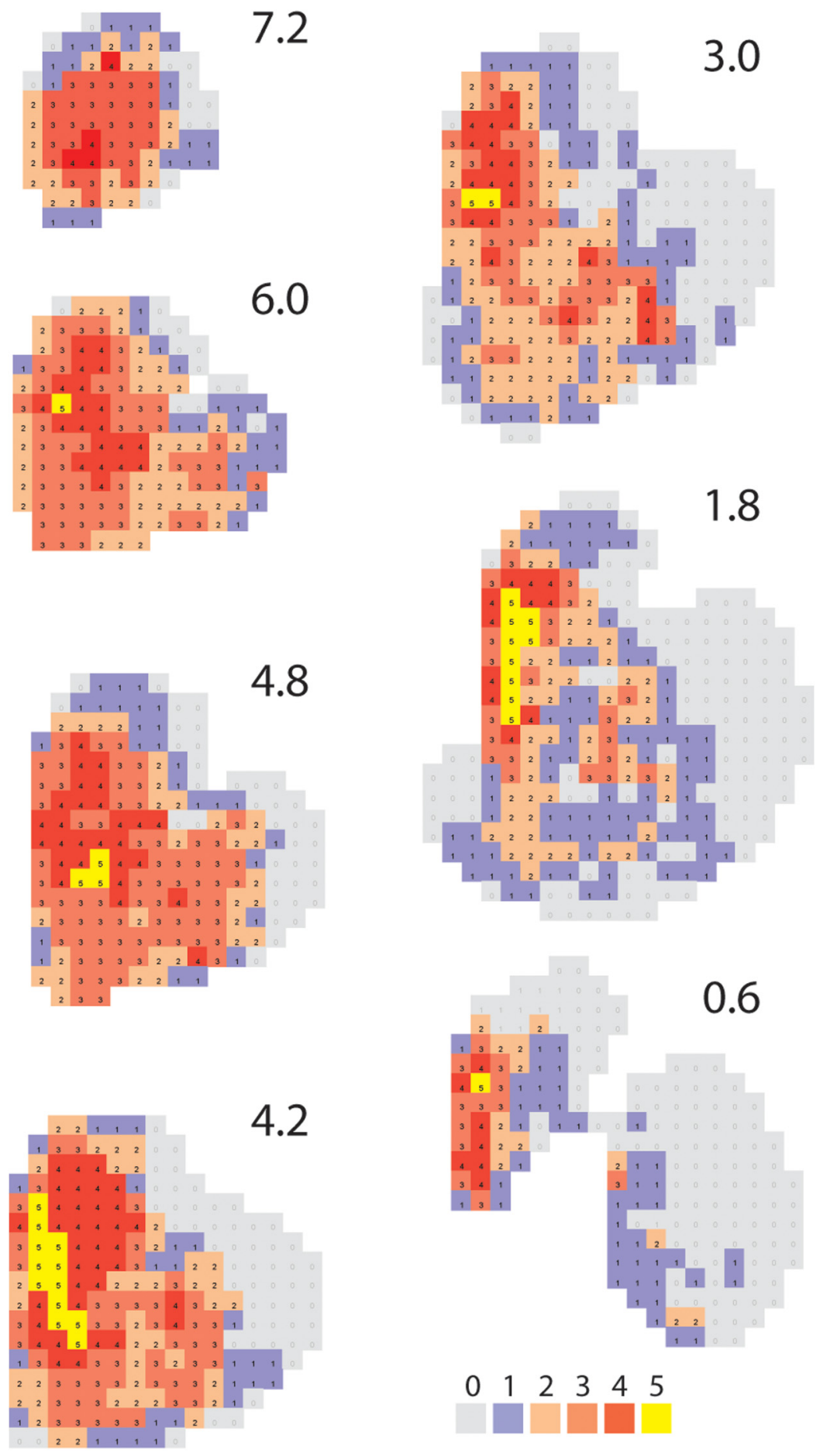

$\begin{array}{lllllll}0 & 1 & 2 & 3 & 4 & 5\end{array}$

Figure 7. Areas of convergence in the striatum. Color on each section indicates voxels that receive projections from 0 to 5 prefrontal cortical regions (i.e., vmPFC, $\mathrm{OFC}, \mathrm{dACC}, \mathrm{dPFC}, \mathrm{vIPFC}$ ). Numbers indicate distance in millimeters anterior to anterior commissure.

Yeterian and Van Hoesen, 1978; Selemon and Goldman-Rakic, 1988; Yeterian and Pandya, 1993), similar to what has been found in frontal cortex. In addition, parietal-frontal areas that share a corticocortical connection project to overlapping zones in the striatum (Yeterian and Van Hoesen, 1978; Selemon and GoldmanRakic, 1988). It does seem that parietal projections tend to be more limited, particularly in their anterior striatal projections, than frontal projections (Kemp and Powell, 1970; Yeterian and Van Hoesen, 1978).

\section{Functional considerations}

There are many hypotheses implicating frontal-striatal networks in specific computations. Specific hypotheses include reinforcement learning (Doya, 2000; Frank, 2005; Dayan and Daw, 2008; Parush et al., 2011), habit formation (Graybiel, 2008), response vigor (Turner and Desmurget, 2010), action selection (Denny-Brown and Yanagisawa, 1976; Mink, 1996; Redgrave et al., 1999; Hikosaka et al., 2000; Hazy et al., 2007), the trade-off between attention demanding and automatically executed actions (Norman and Shallice, 1986; Isoda and Hikosaka, 2007), inhibitory control (Dalley et al., 2011; Jahfari et al., 2011), and the trade-off between habitual and goal-directed actions (Daw et al., 2005). Many of these hypotheses are related and share certain core features. Recent physiological studies suggest that the striatum contains a relatively enriched representation of action value across tasks in which decisions are based either on learning or perceptual inference (Seo et al., 2012). These value representations could underlie most of the other hypotheses, giving rise to action selection or response vigor (toward the most valuable action) and habit formation or motor learning (of an action that was repeatedly reinforced).

There has been growing interest in the idea of broad associative cortical networks, which feature nodes (or connection hubs) that integrate and distribute information across multiple systems (Buckner et al., 2008; Power et al., 2013). These studies indicate that there are specific regions that receive inputs from multiple cortical areas that cross-link between functional systems. Our results suggest that these hubs exist in the striatum as well as the cortex. In particular, the medial, rostral caudate nucleus may serve as a hub for vmPFC, OFC, and dACC to connect with $\mathrm{APFC}$ regions that mediate cognitive control. It is possible that this convergence of cortical areas on specific locations in the striatum may facilitate value computations across diverse domains into a common currency.

\section{Conclusion}

We have shown that the organization of cortical inputs to the striatum is highly regular and can be accounted for by a statistical model that predicts striatal projection zones on the basis of the location of cortical injection sites on a 2-D map. Further, the overlap in striatal projections follows an exponential function with large $(>50 \%)$ overlap in striatal projection zones for cortical injection sites separated by $<5 \mathrm{~mm}$. Sites separated by up to $3 \mathrm{~cm}$, however, still have up to $20 \%$ overlap. In addition, although not specifically considered in our dataset, parietal and frontal cortex have considerable overlap in 
their striatal projection territories, despite being quite distant on the cortical surface (Selemon and Goldman-Rakic, 1985). Finally, we identified a region in the anterior striatum that receives inputs from across the full extent of prefrontal cortex, making this a candidate hub region that can integrate diverse information. Thus, the striatum is a site of convergence for disparate signals arising in cortex. This convergence may facilitate aspects of reinforcement learning that underlie many of the putative functions of the basal ganglia, including habit learning, response vigor, and inhibitory control, as well as providing a unified value representation, across domains.

\section{References}

Alexander GE, DeLong MR, Strick PL (1986) Parallel organization of functionally segregated circuits linking basal ganglia and cortex. Annu Rev Neurosci 9:357-381. CrossRef Medline

Barbas H, Pandya DN (1989) Architecture and intrinsic connections of the prefrontal cortex in the rhesus monkey. J Comp Neurol 286:353-375. CrossRef Medline

Bostan AC, Dum RP, Strick PL (2013) Cerebellar networks with the cerebral cortex and basal ganglia. Trends Cogn Sci 17:241-254. CrossRef Medline

Buckner RL, Andrews-Hanna JR, Schacter DL (2008) The brain's default network: anatomy, function, and relevance to disease. Ann N Y Acad Sci 1124:1-38. CrossRef Medline

Calzavara R, Mailly P, Haber SN (2007) Relationship between the corticostriatal terminals from areas 9 and 46, and those from area $8 \mathrm{~A}$, dorsal and rostral premotor cortex and area $24 \mathrm{c}$ : an anatomical substrate for cognition to action. Eur J Neurosci 26:2005-2024. CrossRef Medline

Carmichael ST, Price JL (1996) Connectional networks within the orbital and medial prefrontal cortex of macaque monkeys. J Comp Neurol 371: 179-207. CrossRef Medline

Christensen R (1997) Log-linear models and logistic regression. New York: Springer.

Cilia R, Cho SS, van Eimeren T, Marotta G, Siri C, Ko JH, Pellecchia G, Pezzoli G, Antonini A, Strafella AP (2011) Pathological gambling in patients with Parkinson's disease is associated with fronto-striatal disconnection: a path modeling analysis. Mov Disord 26:225-233. CrossRef Medline

Dalley JW, Everitt BJ, Robbins TW (2011) Impulsivity, compulsivity, and top-down cognitive control. Neuron 69:680-694. CrossRef Medline

Davis KL, Kahn RS, Ko G, Davidson M (1991) Dopamine in schizophrenia: a review and reconceptualization. Am J Psychiatry 148:1474-1486. Medline

Daw ND, Niv Y, Dayan P (2005) Uncertainty-based competition between prefrontal and dorsolateral striatal systems for behavioral control. Nat Neurosci 8:1704-1711. CrossRef Medline

Dayan P, Daw ND (2008) Decision theory, reinforcement learning, and the brain. Cogn Affect Behav 8:429-453. CrossRef Medline

Denny-Brown D, Yanagisawa N (1976) The role of the basal ganglia in the initiation of movement. In: The basal ganglia (Yahr MD, ed), pp 115-149. New York: Raven.

Doya K (2000) Complementary roles of basal ganglia and cerebellum in learning and motor control. Curr Opin Neurobiol 10:732-739. CrossRef Medline

Draganski B, Kherif F, Klöppel S, Cook PA, Alexander DC, Parker GJ, Deichmann R, Ashburner J, Frackowiak RS (2008) Evidence for segregated and integrative connectivity patterns in the human basal ganglia. J Neurosci 28:7143-7152. CrossRef Medline

Ersche KD, Jones PS, Williams GB, Turton AJ, Robbins TW, Bullmore ET (2012) Abnormal brain structure implicated in stimulant drug addiction. Science 335:601-604. CrossRef Medline

Frank MJ (2005) Dynamic dopamine modulation in the basal ganglia: a neurocomputational account of cognitive deficits in medicated and nonmedicated Parkinsonism. J Cogn Neurosci 17:51-72. CrossRef Medline

Goodman WK, Foote KD, Greenberg BD, Ricciuti N, Bauer R, Ward H, Shapira NA, Wu SS, Hill CL, Rasmussen SA, Okun MS (2010) Deep brain stimulation for intractable obsessive compulsive disorder: pilot study using a blinded, staggered-onset design. Biol Psychiatry 67:535542. CrossRef Medline

Graybiel AM (2008) Habits, rituals, and the evaluative brain. Annu Rev Neurosci 31:359-387. CrossRef Medline

Haber SN, Kim KS, Mailly P, Calzavara R (2006) Reward-related cortical inputs define a large striatal region in primates that interface with asso- ciative cortical connections, providing a substrate for incentive-based learning. J Neurosci 26:8368-8376. CrossRef Medline

Hastie T, Tibshirani RJ, Friedman J (2001) The elements of statistical learning. New York: Springer.

Hazy TE, Frank MJ, O’Reilly RC (2007) Towards an executive without a homunculus: computational models of the prefrontal cortex/basal ganglia system. Philos Trans R Soc Lond B Biol Sci 362:1601-1613. CrossRef Medline

Hikosaka O, Takikawa Y, Kawagoe R (2000) Role of the basal ganglia in the control of purposive saccadic eye movements. Physiol Rev 80:953-978. Medline

Isoda M, Hikosaka O (2007) Switching from automatic to controlled action by monkey medial frontal cortex. Nat Neurosci 10:240-248. CrossRef Medline

Jahfari S, Waldorp L, van den Wildenberg WP, Scholte HS, Ridderinkhof KR, Forstmann BU (2011) Effective connectivity reveals important roles for both the hyperdirect (fronto-subthalamic) and the indirect (frontostriatal-pallidal) fronto-basal ganglia pathways during response inhibition. J Neurosci 31:6891-6899. CrossRef Medline

Kegeles LS, Abi-Dargham A, Frankle WG, Gil R, Cooper TB, Slifstein M, Hwang DR, Huang Y, Haber SN, Laruelle M (2010) Increased synaptic dopamine function in associative regions of the striatum in schizophrenia. Arch Gen Psychiatry 67:231-239. CrossRef Medline

Kelly RM, Strick PL (2004) Macro-architecture of basal ganglia loops with the cerebral cortex: use of rabies virus to reveal multisynaptic circuits. Prog Brain Res 143:449-459. Medline

Kemp JM, Powell TP (1970) The cortico-striate projection in the monkey. Brain 93:525-546. CrossRef Medline

Kennerley SW, Walton ME (2011) Decision making and reward in frontal cortex: complementary evidence from neurophysiological and neuropsychological studies. Behav Neurosci 125:297-317. CrossRef Medline

Kennerley SW, Behrens TE, Wallis JD (2011) Double dissociation of value computations in orbitofrontal and anterior cingulate neurons. Nat Neurosci 14:1581-1589. CrossRef Medline

Kremer JR, Mastronarde DN, McIntosh JR (1996) Computer visualization of three-dimensional image data using IMOD. J Struct Biol 116:71-76. CrossRef Medline

Menard SW (2002) Applied logistic regression analysis, 2nd Edition. Thousand Oaks, CA: Sage.

Middleton FA, Strick PL (2000) Basal ganglia and cerebellar loops: motor and cognitive circuits. Brain Res Brain Res Rev 31:236-250. CrossRef Medline

Mink JW (1996) The basal ganglia: focused selection and inhibition of competing motor programs. Prog Neurobiol 50:381-425. CrossRef Medline

Norman DA, Shallice T (1986) Attention to action willed and automatic control of behavior. In: Consciousness and self-regulation. Advances in research and theory (Davidson RJ, Schwartz GE, Shapiro D, eds), pp 1-18. New York: Plenum.

O’Doherty J, Dayan P, Schultz J, Deichmann R, Friston K, Dolan RJ (2004) Dissociable roles of ventral and dorsal striatum in instrumental conditioning. Science 304:452-454. CrossRef Medline

Padoa-Schioppa C, Assad JA (2006) Neurons in the orbitofrontal cortex encode economic value. Nature 441:223-226. CrossRef Medline

Pantelis C, Barnes TR, Nelson HE, Tanner S, Weatherley L, Owen AM, Robbins TW (1997) Frontal-striatal cognitive deficits in patients with chronic schizophrenia. Brain 120:1823-1843. CrossRef Medline

Parush N, Tishby N, Bergman H (2011) Dopaminergic balance between reward maximization and policy complexity. Front Syst Neurosci 5:22. CrossRef Medline

Paxinos G, Huang X-F, Toga AW (2000) The rhesus monkey brain in stereotaxic coordinates. New York: Academic.

Petrides M, Pandya DN (2002) Comparative cytoarchitectonic analysis of the human and the macaque ventrolateral prefrontal cortex and corticocortical connection patterns in the monkey. Eur J Neurosci 16:291-310. CrossRef Medline

Power JD, Schlaggar BL, Lessov-Schlaggar CN, Petersen SE (2013) Evidence for hubs in human functional brain networks. Neuron 79:798-813. CrossRef Medline

Redgrave P, Prescott TJ, Gurney K (1999) The basal ganglia: a vertebrate solution to the selection problem? Neuroscience 89:1009-1023. CrossRef Medline

Roesch MR, Olson CR (2007) Neuronal activity related to anticipated re- 
ward in frontal cortex: does it represent value or reflect motivation? Ann N Y Acad Sci 1121:431-446. CrossRef Medline

Schultz W, Tremblay L, Hollerman JR (2003) Changes in behavior-related neuronal activity in the striatum during learning. Trends Neurosci 26: 321-328. CrossRef Medline

Selemon LD, Goldman-Rakic PS (1985) Longitudinal topography and interdigitation of corticostriatal projections in the rhesus monkey. J Neurosci 5:776-794. Medline

Selemon LD, Goldman-Rakic PS (1988) Common cortical and subcortical targets of the dorsolateral prefrontal and posterior parietal cortices in the rhesus monkey: evidence for a distributed neural network subserving spatially guided behavior. J Neurosci 8:4049-4068. Medline

Seo M, Lee E, Averbeck BB (2012) Action selection and action value in frontal-striatal circuits. Neuron 74:947-960. CrossRef Medline

Takikawa Y, Kawagoe R, Hikosaka O (2002) Reward-dependent spatial selectivity of anticipatory activity in monkey caudate neurons. J Neurophysiol 87:508-515. Medline

Turner RS, Desmurget M (2010) Basal ganglia contributions to motor control: a vigorous tutor. Curr Opin Neurobiol 20:704-716. CrossRef Medline van den Heuvel OA, van der Werf YD, Verhoef KM, de Wit S, Berendse HW, Wolters ECh, Veltman DJ, Groenewegen HJ (2010) Frontal-striatal abnormalities underlying behaviours in the compulsive-impulsive spectrum. J Neurol Sci 289:55-59. CrossRef Medline

Wallis JD, Kennerley SW (2011) Contrasting reward signals in the orbitofrontal cortex and anterior cingulate cortex. Ann N Y Acad Sci 1239:33-42. CrossRef Medline

Weinberger DR, Berman KF, Daniel DG (1992) Mesoprefrontal cortical dopaminergic activity and prefrontal hypofunction in schizophrenia. Clin Neuropharmacol 15 [Suppl 1] Pt A:568A-569A. Medline

Yeterian EH, Pandya DN (1991) Prefrontostriatal connections in relation to cortical architectonic organization in rhesus monkeys. J Comp Neurol 312:43-67. CrossRef Medline

Yeterian EH, Pandya DN (1993) Striatal connections of the parietal association cortices in rhesus monkeys. J Comp Neurol 332:175-197. CrossRef Medline

Yeterian EH, Van Hoesen GW (1978) Cortico-striate projections in the rhesus monkey: the organization of certain cortico-caudate connections. Brain Res 139:43-63. CrossRef Medline 